\title{
ACOUSTICAL DISSIPATION \\ IN SOME TETRAHEDRALLY-BONDED SEMICONDUCTING COMPOUNDS
}

\author{
S.K. Kor AND P. MEHrotra \\ Department of Physics, University of Allahabad, Allahabad 211002, India
}

(Received December 13, 1994)

\begin{abstract}
Phonon-phonon coupling and thermoelastic relaxation are the principal thermal causes of ultrasonic attenuation in solids at room temperature. Second order elastic moduli and third order elastic moduli have been used to study the ultrasonic attenuation suffered by compressional and shear acoustic waves for some tetrahedrally bonded semiconducting materials, viz. GaP, In $P$ and In As along $\langle 100\rangle,\langle 110\rangle$ and $\langle 111\rangle$ crystallographic directions. Attenuation in case of $\operatorname{In} \mathrm{P}$ is found to be quite large as compared to $\mathrm{GaP}$ and InAs. The reason behind this discrepancy is due to doping of $\mathrm{Cr}$ in $\operatorname{InP}$ sample and it is also seen that ultrasonic attenuation due to phonon-phonon interaction dominates over that due to thermoclastic relaxation.
\end{abstract}

PACS numbers: $62.20 .-\mathrm{x}, 62.65 .+\mathrm{k}, 62.80 .+\mathrm{f}$

\section{Introduction}

The properties of semiconducting elements of the fourth group of the periodic table have been extensively studied $[1,2]$, the corresponding properties of the III-V group compounds have been investigated rather recently. A useful technique for investigating the physical properties of solids is to find out the characteristics of acoustical wave propagation in them. Such study has been done only for few semiconducting compounds. The aim of the present paper is to investigate the dissipation of energy due to (i) thermal relaxation and (ii) coupling of thermal phonons with the phonons of acoustical wave propagating through these materials. This has been considered for the three important crystallographic directions $\langle 100\rangle$, $\langle 110\rangle$ and $\langle 111\rangle$ for longitudinal wave as well as for transverse waves for different state of polarization for GaP, In As and $\operatorname{In} P$.

\section{Theory}

The physical basis for obtaining attenuation coefficient is that the elastic constants [3] are contributed by the thermal phonons relaxation. The phonon contribution to the unrelaxed elastic constants is evaluated by taking into consideration the change in energy of the thermal phonon when applied on instantaneous 
strain. The frequency of each mode $\nu_{i}$ is changed by $\mathrm{d} \nu_{i} / \nu_{i}=-\gamma_{i}^{j} S_{j}$, where $\gamma_{i}^{j}$ is generalised Grüneisen parameter and $S_{j}$ is instantaneous strain. It is assumed that all the phonons of a given propagation direction and polarization have equal change of frequency. Then phonons of each branch $i$ experience a temperature change $\Delta T_{i} / T_{0}=-\gamma_{i}^{j} S_{j}, T$ being the temperature. A relaxed constant is obtained after there is phonon-phonon coupling among the various branches and the $\Delta T_{i}$ relax to a common temperature change $\Delta T$ given by $\Delta T / T=-\left\langle\gamma_{i}^{j}\right\rangle S_{j}$ where $\left\langle\gamma_{i}^{j}\right\rangle$ is average value of $\gamma_{i}^{j}$. Thermal relaxation time is of the order of thermal conductivity relaxation time and is given by

$$
\tau=\frac{3 k}{C_{v} \bar{v}^{2}}
$$

where $k, C_{v}$ and $\bar{v}$ are the thermal conductivity, specific heat per unit volume and Debye average ultrasonic velocity, respectively. With the help of the relaxed and unrelaxed elastic moduli the attenuation of acoustic wave has been obtained as (for $w \tau \ll 1$ ):

$$
\left(\alpha / f^{2}\right)_{\mathrm{p}-\mathrm{p}}= \begin{cases}\frac{4 \pi^{2} E D \tau}{3 \varrho \bar{v}^{3}} & \text { for longitudinal wave, } \\ \frac{2 \pi^{2} E D \tau}{3 \varrho \bar{v}^{3}} & \text { for shear wave, }\end{cases}
$$

where

$$
\dot{D}=\left[9 E\left\langle\left(\gamma_{i}^{j}\right)^{2}\right\rangle-3 C_{v} T\left\langle\gamma_{i}^{j}\right\rangle^{2}\right] / E,
$$

$E$ and $\varrho$ being crystal energy and density of the material.

The cause of thermoelastic loss is due to the flow of heat from a compressed part to the rarefied part of the wave. This loss occurs only from a longitudinal acoustic wave, because in the case of transverse waves there is no change in volume and hence no conduction losses. The expression for thermoelastic relaxation was obtained as

$$
\left(\alpha / f^{2}\right)_{\mathrm{t}-\mathrm{e}}=\frac{4 \pi^{2}\left\langle\gamma_{i}^{j}\right\rangle^{2} k T}{2} \frac{1}{\bar{v}_{l}^{5}}
$$

for semiconductors, the effect should be small due to thermal expansion and thermal conductivity and the same has been verified in the present work.

\section{Evaluation}

From the available data $[4,5]$ of second and third order elastic constants, $\left\langle\gamma_{i}^{j}\right\rangle^{2}$ and $\left\langle\gamma_{i}^{j 2}\right\rangle$ have been evaluated for different directions of propagation. The corresponding values of non-linearity parameter is also obtained. The thermodynamic data [6,7] and values of physical constants [8] have been taken from the literature.

\section{Results and discussions}

Table enlists the attenuation values due to phonon-phonon coupling and loss due to thermoelastic relaxation along various crystallographic directions at 
TABLE

Altenuation of longitudinal and shear ultrasonic wave. $p-p$ represents the phonon viscosity loss in $10^{-18} \mathrm{~dB} \mathrm{~s}^{2} / \mathrm{cm}, \mathrm{t}-\mathrm{e}$ represents thermoelastic relaxation loss in $10^{-20} \mathrm{~dB} \mathrm{~s}^{2} / \mathrm{cm}$.

\begin{tabular}{|c|c|c|c|c|c|c|c|c|c|}
\hline \multirow{3}{*}{$\begin{array}{l}\text { Comp- } \\
\text { ound }\end{array}$} & \multirow{3}{*}{$\begin{array}{l}\text { Attenu- } \\
\text { ation }\end{array}$} & \multicolumn{8}{|c|}{ Direction of propagation } \\
\hline & & \multicolumn{2}{|c|}{$\langle 100\rangle$} & \multicolumn{3}{|c|}{$\langle 110\rangle$} & \multicolumn{3}{|c|}{$\langle 111\rangle$} \\
\hline & & Long. & Shear & Long. & Shear ${ }^{a}$ & Shear $^{b}$ & Long. & Shear $^{c}$ & Shear $^{d}$ \\
\hline \multirow[t]{2}{*}{$\mathrm{GaP}$} & $\left(\alpha / f^{2}\right)_{\mathrm{p}-\mathrm{p}}$ & 5.0 & \multirow[t]{2}{*}{0.9} & 8.9 & \multirow[t]{2}{*}{2.4} & \multirow[t]{2}{*}{2.9} & 9.4 & \multirow[t]{2}{*}{4.0} & \multirow[t]{2}{*}{4.8} \\
\hline & $\left(\alpha / f^{2}\right)_{t-e}$ & 8.7 & & 9.2 & & & 4.9 & & \\
\hline \multirow[t]{2}{*}{ InAs } & $\left(\alpha / f^{2}\right)_{\mathrm{p}-\mathrm{p}}$ & 12.3 & \multirow[t]{2}{*}{3.7} & 37.0 & \multirow[t]{2}{*}{18.5} & \multirow[t]{2}{*}{2.8} & 38.8 & \multirow[t]{2}{*}{9.8} & \multirow[t]{2}{*}{6.8} \\
\hline & $\left(\alpha / f^{2}\right)$ & 13.7 & & 23.8 & & & 8.5 & & \\
\hline \multirow[t]{2}{*}{ InP } & $\left(\alpha / f^{2}\right)_{\mathrm{p}-\mathrm{p}}$ & 245.4 & \multirow[t]{2}{*}{112.8} & 172.4 & \multirow[t]{2}{*}{564.8} & \multirow[t]{2}{*}{406.0} & 453.6 & \multirow[t]{2}{*}{817.0} & \multirow[t]{2}{*}{798.0} \\
\hline & $\left(\alpha / f^{2}\right)_{1-e}$ & 2.1 & & 7.7 & & & 2.9 & & \\
\hline
\end{tabular}

room temperature. From Table one infers that the values of $\left(\alpha / f^{2}\right)$ along different directions of propagation are unequal as in $\mathrm{GaAs}$ and $\mathrm{InSb}$ [9]. The present values of ultrasonic attenuation due to phonon viscosity loss and thermoelastic relaxation for $\mathrm{GaP}$ and InAs are comparable with other semiconducting crystals but in case of InP phonon, viscosity loss is very high along all the considered directions of propagation. The reason for this discrepancy in InP may be attributed to its extrinsic semiconducting nature - the crystal of $\mathrm{InP}$ chosen for this study is $\mathrm{Cr}$ doped, $n$-type InP. Doping by $\mathrm{Cr}$ in InP, which increases the conductivity of the crystals, is accompanied by an increase in the non-linearity constant $D$ and hence increase in the value of phonon viscosity. The piezoelectric contribution [10] to the attenuation in Cr-doped $\mathrm{InP}$ in $\langle 111\rangle$ longitudinal direction is experimentally found to be about $120 \mathrm{~dB} \mathrm{~s}^{2} / \mathrm{cm}$; approximately one fourth of the total attenuation, thus confirming the correctness of our results. The thermoelastic loss along $\langle 100\rangle,\langle 110\rangle$ and $\langle 111\rangle$ directions evaluated for all the three compounds is very small compared to phonon viscosity loss which reveals the fact that a major part of the acoustic energy loss is used in achieving equilibrium among various phonon branches and directions.

\section{References}

[1] U.S. Tandon, S.K. Kor, Phys. Rev. B 7, 4640 (1973).

[2] S.K. Kor, R.P. Khare; Phys. Lett. A 76, 427 (1980).

[3] J. Blitz, Fundamental of Ultrasonics, Butterworth, London 1967.

[4] Y.K. Yogurteu, A.J. Miller, G.A. Saunders, J. Phys. Chem. Solids 42, 49 (1981).

[5] D.N. Nichols, D.S. Rimai, R.J. Sladek, Solid State Commun. 36, 667 (1980).

[6] W. Nakwaski, J. Appl. Phys. 64, 159 (1988).

[7] H.M. Kagaya, T. Soma, Solid State Commun. 58, 479 (1986).

[8] The Practicing Scientists Handbook, Ed. A.J. Moses, Von Nostrand, Holland 1978.

[9] S.K. Kor, N.D. Tripathi, J. Appl. Phys. 46, 467 (1975).

[10] W.F. Boyle, R.J. Sladek, Solid State Commun. 16, 323 (1975). 